\title{
Current Symptoms of Depression at the National Psychiatric Hospital of Thiaroye
}

\author{
Ndiaye-Ndongo Ndèye Dialé, Sylla Aida, Bague Boubacar, Fall Lamine, \\ Thiam Mamadou Habib \\ Service de Psychiatrie du CHNU Fann, Dakar, Sénégal \\ Email: dialouchandongo@yahoo.fr
}

Received 2 April 2015; accepted 15 May 2015; published 18 May 2015

Copyright (C) 2015 by authors and Scientific Research Publishing Inc.

This work is licensed under the Creative Commons Attribution International License (CC BY). http://creativecommons.org/licenses/by/4.0/

c) (i) Open Access

\begin{abstract}
Depression is a complex disorder which requires a degree of subtle knowledge of its various clinical expressions in order to be able to provide treatment at an early stage. In light of changes in families and patients, the authors engaged in a psychiatric study of current symptoms of depression. A retrospective study was carried out at the National Psychiatric Hospital of Thiaroye in Senegal from January 1st to December 31st of 2011. It related to the clinical observation of outpatients who had been diagnosed with depression. We found that insomnia occurred most frequently (73.9\%), followed by somatic complaints (34.3\%). Hallucinations and cenesthopathies occurred in $14.0 \%$ and $12.6 \%$ of cases, which was much less frequent than what had been observed previously. Symptoms such as delirious ideas are no longer the most common aspect of depression. Suicidal thoughts were found to be more frequent than in prior studies, although the tendency to act on these thoughts was still less than before. Thus, societal changes have had an impact on the expression of depressive disorders, and mental health experts should take heed of this.
\end{abstract}

\section{Keywords}

Depression, Symptoms, Senegal

\section{Introduction}

Depression is a pathological condition involving mental anguish and conscious guilt that is accompanied by decreased self esteem, psychomotor disturbances as well as somatic symptoms.

The diagnosis of depression is straightforward with the more typical forms of this condition. There are, however, numerous symptomatic and progressive clinical forms, some of which can be misleading. These can hence pose an immediate life threatening risk depending on the potential suicide threat level. 
In Africa, depression was initially considered to be non-existent, then rare, and ultimately as exhibiting specific characteristics (Collomb, 1962; Diop, 1961; Bourgeois, 1986).

In Senegal, there has been a lot of work regarding depression. In light of the development of lifestyles associated with progressive urbanization in the context of globalization, it seemed opportune to us to investigate the current symptoms of depression in a psychiatric environment.

\section{Patients and Methods}

We carried out a retrospective, descriptive and cross-sectional study at the National Psychiatric Hospital Center of Thiaroye in Senegal. Clinical observations were compiled of outpatients who were examined between the 1st of January and the 31st of December 2011 and who were diagnosed with depression. It was about all the patients who had the diagnosis of depression during the period of study taken at the registry of examination. They signed a informed consent prior to data collection.

The data was generated through use of a questionnaire (see Appendix). The investigation was performed starting with observation of the patients and it was completed by using the records from the consultations.

The data were compiled using Epi Info version 6.04 software. Comparisons were done using the Chi-squared test.

\section{Results}

Two-hundred and seventy patients were evaluated.

The most affected age group was from 45 to 50 years of age.

Women exhibited depression more often than men, with 151 females, or $72.95 \%$, versus 56 males.

Married patients represented $63.76 \%$. There were $14 \%$ who were single versus $5 \%$ who were divorced. Widows represented $11.19 \%$, while there was not one widower in the study population.

Depression was the 4th most common pathology diagnosed at the Thiaroye NPHC, with a frequency of $8.86 \%$, following behind schizophrenia at $22.35 \%$, various manifestations of delirious spells at $21.31 \%$, and toxic psychoses at $9.12 \%$.

Prior incidents of psychosis were encountered with 24 patients, or $11.59 \%$.

Nineteen patients had a family history of psychiatric illness, or $9.2 \%$ of the study population.

The majority of patients presenting with depression were treated as outpatients.

\section{The Encountered Symptoms (Figure 1)}

Insomnia was the most common symptom, occurring with $73.9 \%$ of the patients exhibiting depression. Somatic complaints occurred with $34.3 \%$. Seventy, i.e. $33.81 \%$, of the patients refused to eat. Sixty-nine patients, i.e. $33.3 \%$, exhibited sadness. As far as suicidal thoughts are concerned, these occurred with 45 patients, i.e. $21.7 \%$. Twelve patients attempted suicide, i.e. 5.8\%. Delirium occurred with 33 patients, i.e. 15.95\%.Thirty-one patients presented with an anxiety, i.e. 15\%. Agitation was encountered with 29 patients, i.e. $14 \%$, hallucinations with 29 patients, i.e. $14 \%$. A decrease in psychomotor activity occurred with 23 patients, i.e. $11.1 \%$, with a clinophilia for $3.4 \%$.

\section{Discussion}

\subsection{Frequency of the Symptoms}

Our study has revealed an elevated frequency of insomnia (73.9\%) followed by somatic complaints (34.3\%), eating disorders (33.81\%) and sadness (33.3\%).

This frequency order of the symptoms does not match the standard description of depression with three types of common symptoms: bad moods, decreased psychomotor activity, and disrupted instinctual functions with difficulties relating to sleep, appetite and libido (Ey, 1954).

This non-standard order appears more common, however, for depressive states in Senegal, where insomnia, somatic complaints, eating disorders, sadness and suicidal thoughts dominated. Decreased psychomotor activity, which is typically thought of as being central to depression syndromes, is very uncommon though in Senegal.

Ahyi found a prevalence of sadness, somatic symptoms - such as gastric conditions in particular - and delusions of being persecuted (Ahyi, 1977). 


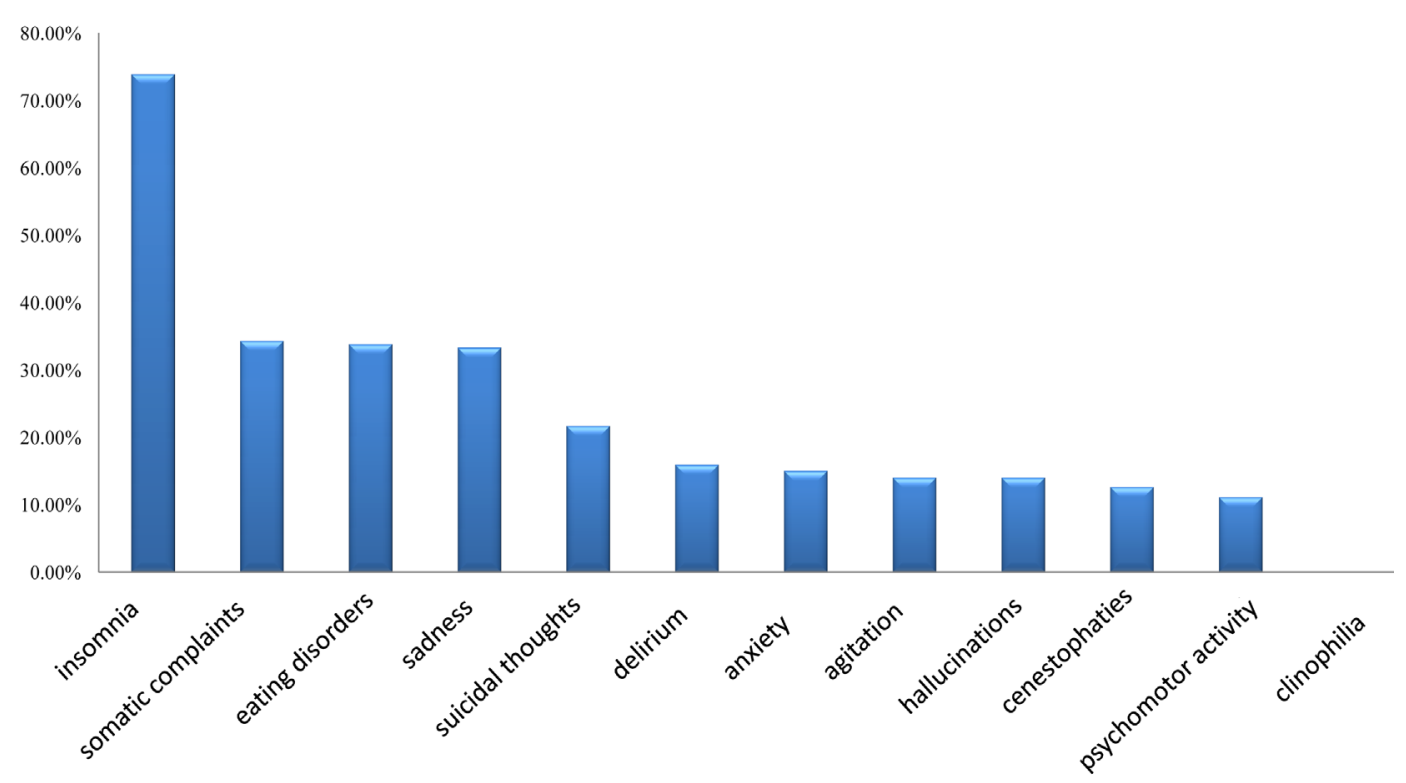

Figure 1. The frequency of depression symptoms that were encountered.

\subsection{Insomnia}

It was the most common symptom among depressed patients. One hundred and fifty-four patients exhibited insomnia, i.e. $73.9 \%$. This occurred equally among men and women as $73.2 \%$ and $74.2 \%$, respectively. This is counter to the findings of Ahyi, who found a prevalence of somatic complaints (Ahyi, 1977).

In our setting, these sleep disorders were easier to express verbally than other problems. This explains why they were raised at the first encounter with the psychiatrist, as they clearly represent an annoying symptom.

\subsection{Somatic Complaints}

These constituted the second most frequent symptom found with our series. Seventy-one patients expressed somatic complaints, i.e. $34.3 \%$.Women $(37.7 \%)$ more often expressed somatic complaints than men $(25 \%)$. They were mainly headaches at $65.7 \%$, asthenia at $1.45 \%$, constipation at $1.45 \%$, and dysmenorrhea, palpitations, abdominal pains, precordialgias.

Karfo has shown that somatic complaints are the main reason for seeking a medical consultation (Karfo, Sanou, Yaogo, Ouango, \& Ouedraogo, 2009). Other authors have shown that depression in Africa has specific clinical features, with somatic complaints being acknowledged first (Collomb, 1962; Diop, 1961; Bourgeois, 1986). Somatic complaints can hence be at the top of the list, thereby jeopardizing diagnosis of the mental illness. These somatic complaints therefore constitute depression in disguise, whereby the recurrent complaints are suggestive of a physical pathology.

This variant is understandable given the stigma of psychiatric problems. Physical problems, also known as bodily ailments, are more palatable to the individual as well as those around them, than psychiatric problems which are seen as an illness of the soul.

At the first interview with the doctor, the physical ailments are raised as they are more accessible to the latter.

\subsection{Eating Disorders}

These occurred with $33.81 \%$ of the patients. They constituted the third most common symptom. These problems correspond with a refusal to eat, and these authors typically see this as being essentially equivalent to a suicidal tendency: they are an indication of being opposed to one's own life and of passively seeking death (Lempèrière, Feline, Ades, Hardy, \& Rouillon, 2006). These equivalents of suicide often consist of letting oneself die by loss of will, which to a certain extent is similar to the classical failure-to-thrive syndrome of geriatric cachexia (Barbier, 2006). 


\subsection{Sadness}

This constituted the fourth most common symptom in our study. Sixty-nine patients exhibited sadness, i.e. 33.3\%. It is much the same between men and women.

Ahyi found that sadness was the most common symptom, with 111 out of 246 observations (Ahyi, 1977).

The fact that feelings are expressed more rarely than they are recognized may explain our results.

\subsection{Suicidal Thoughts and Suicide Attempts}

The frequencies of suicidal ideas and suicide attempts were $21.7 \%$ and $5.8 \%$, respectively.

We found that suicidal thoughts were more common with men $(26.8 \%)$ than with women (19.9\%). The same trend was seen with suicide attempts, accounting for $7.1 \%$ of men and $5.3 \%$ of women. The means used to commit this act are diverse, and include jumping from a building, bleeding oneself to death, and intentional medication overdoses.

In Senegal, M'boussou noted 53 suicide attempts among 417 mentally ill individuals. Furthermore, he emphasized that suicidal thoughts could be found in the files of 21 individuals, i.e. 13.6\% (M'boussou, 1981).

The percentage of suicides that we encountered contrasts with what has been seen in France (Barbier, 2003).

Our results may be explained by the fact that while Senegalese may entertain thoughts of suicide relatively frequently, actually going through with the act remains a rare occurrence. This seems to be due to the Senegalese cultural beliefs which condemn suicide regardless of one's religious background or affiliation (e.g. Muslim or Christian). Family unity and support from acquaintances are also effective ways through which Africans avoid stooping to this course of action. Indeed, Barbier reported: "In industrialized societies where loneliness abounds and being overworked is common etc., one in ten individuals will experience depression in their life with a recurrent state of depression in more than half of these cases. It is in fact the cause of two thirds of all suicide deaths" (Barbier, 2003). Religion and social support therefore appear to be protective factors.

This can equally be explained by the taboo and shame associated with this act and with suicidal thoughts. Face to face with a doctor, patients often feel embarrassed to freely express the suicidal thoughts that they harbor. Their increase relative to what was seen in earlier studies in Senegal should however be an issue of concern to practitioners (Ahyi, 1977; Collomb \& Collignon, 1974). It needs to be seen to what extent an increasingly urban life style with a more and more pronounced degree of isolation plays a part in this.

\section{Anxiety}

This occurred with $15 \%$ of the patients. Authors such as Blazer and Baldwin have found that anxiety is very often a feature of depression as general anxiety or as phobias (Blazer, 2003; Burns, Dening, \& Lawlor, 2002; Baldwin, Chiu, Katona, \& Graham, 2002).

Collomb found that anxiety and the manifestation of hypochondria were frequent occurrences with depression (Collomb, 1962).

The rarity of anxiety in our study may be explained by the fact that it can go unnoticed. It is a subjective element that can be underappreciated by the doctor. This anxiety can however be masked and it may trigger hostile unrest particularly in the elderly (Fremont, 2004).

\subsection{Agitation}

This occurred with $14 \%$ of the patients. According to Goldberg, maniacal symptoms - mainly absent mindedness, a loss of ideas, and psychomotor agitation — can occur during a period of depression without amounting to a mixed depressive syndrome (Goldberg, Perlis, Bowden et al., 2009).

Benazzi performed a similar study with depressed patients and he encountered maniacal symptoms, including agitation, with $32 \%$ of patients (Benazzi, 2004).

It is generally acknowledged that maniacal symptoms, including agitation, constitute a poor prognosis since they may be triggers of development of a bipolar disorder, with bouts occurring in rapid succession, and they are associated with an early onset of the disorders (Goldberg, Perlis, Bowden et al., 2009).

Their occurrence is associated with more suicide attempts (Judd, Akiskal, Schttler et al., 2003). 


\subsection{Decreased Psychomotor Activity}

This is considered by some authors as lying at the core of the depressive syndrome (Parker, \& Melancholia, 1996). Evidence of decreased psychomotor activity was present with $11.1 \%$ of the patients in our series.

Our results show that a slowdown in psychomotor activity was rare among depressed individuals in Senegal. The slowdown of motor function is not often an issue that is raised by the patient as they have come to view it as normal, since "when one is ill, one is weaker and thus more in need of having to lie down".

\subsection{Hallucinations}

These occurred with $14.0 \%$ and $12.60 \%$, respectively.

Hallucinations are based on a theme of persecution. It is commonly either the marabout of one's co-spouse or it is the evil eye.

Collomb, Ahyi, \& M'boussou came across the same theme in their studies, albeit at higher levels (Collomb, 1962; M'boussou, 1981; Ahyi, 1977). Increased knowledge and a higher level of medication could underlie this change in the explanation of depression symptoms. Indeed, psychiatrists trained in France were less likely to be sought for consultation at the onset of the illness. Rather, treatment of psychiatric symptoms was more readily assigned to traditional healers (Collomb, 1962; Collomb \& Collignon, 1974).

\subsection{Delirious Ideas}

These occurred with $15.94 \%$ of the patients. They are essentially ideas of persecution and self-accusatory selfdeprecation. M'boussou found that the persecution theme was the most prevalent. He considered it a key symptom, closely linked with black African culture (M'boussou, 1981).

Ahyi found that delirious ideas of persecution occur very frequently in the course of depressive states. $\mathrm{He}$ states that after somatic complaints, deliriums of persecution constitute the second most common characteristic of the depressive state in the Senegalese (Ahyi, 1977). Collomb in turn affirmed the rarity of melancholy, suicidal tendencies, indignant rantings, self-accusations, and guilt among depressed Senegalese (Collomb, 1962).

Ideas about persecution are not prominent during bouts of depression. They take a backseat to somatic complaints. The depressed Senegalese patients in our study had less of a tendency to accuse others for their suffering. Could this indicate that there is less projection, and more calling into question and self-criticism?

The notion of mental illness has therefore changed, prompting acceptance of the medical explanation of specific psychiatric scenarios.

\subsection{The Other Symptoms}

Symptoms such as anhedonia (4.8\%) and clinophilia (M'boussou, 1981; Ahyi, 1977) were rare events in our study's series.

Thiam found that, in Senegal, loss of interest in habitual interests was part of the main symptoms of depression (Thiam, Karfo, Sylla, Dassa, Sy, Ba, Faye, \& Gueye, 2008).

The rarity of these symptoms may be explained by the fact that they are not probed for systematically.

\section{Conclusion}

The adverse effects of depression appear to currently mainly occur as insomnia (73.9\%) followed by somatic complaints (34.3\%), eating disorders (33.81\%) and sadness (33.3\%). We noted a slight increase in suicidal thoughts and suicide attempts. Delirious ideas, particularly those pertaining to persecution, were found to occur less than what had been seen previously.

Social transformation and changes in outlook may therefore not be inconsequential in terms of the expression of the adverse effects of depression. It will be necessary to assess the role of a more urbanized lifestyle that can lead to more and more individual isolation in this effect.

\section{Conflict of Interest}

None. 


\section{References}

Ahyi, R. G. (1977). Les états dépressifs au Sénégal à propos de 246 observations (141 p). Dakar: Thèse de Médecine, Université Cheikh Anta Diop de Dakar.

Baldwin, R. C., Chiu, E., Katona, C., \& Graham, N. (2002). Guidelines on Depression in Older People (162 p). Londres: Martin Dunitz.

Barbier, D. (2003). La dépression: Santé au Quotidien (226 p).

Benazzi, F. (2004). Intra-Episode Hypomanic Symptoms during Major Depression and Their Correlates. Psychiatry and Clinical Neurosciences, 58, 289-294. http://dx.doi.org/10.1111/j.1440-1819.2004.01234.x

Blazer, D. G. (2003). Depression in Late Life: Review and Commentary. The Journals of Gerontology: Series A, 58, 249-265. http://dx.doi.org/10.1093/gerona/58.3.M249

Bourgeois, M. (1986). Sens du désespoir. Compte rendu de la journée psychiatrique d'Aquitaine.

Burns, A., Dening, T., \& Lawlor, B. (2002). Clinical Guidelines in Old Age Psychiatry (208 p). Londres: Martin Dunitz.

Collomb, H. Z. J. (1962). Les états dépressifs en milieu africain. Information Psychiatrique, 6, 515-528.

Collomb, H., \& Collignon, R. (1974). Les conduites suicidaires en Afrique. Psychopathologie Africaine, X, 55-113.

Diop, M. (1961). La dépression chez le Noir Africain. Bulletins et memoires de la Faculte mixte de medecine et de pharmacie de Dakar, $I X, 247-253$.

Ey, H. (1954). Etudes Psychiatriques. In D. De Brouwer (Ed.), Structure des psychoses aiguës et déstructuration de la conscience (pp. 653-760). Paris: Desclée de Brouwer.

Fremont, P. (2004). Aspects cliniques de la dépression du sujet âgé. Psycholneuropsychiatr Vieillissement, 2, S19-S27.

Goldberg, J. F., Perlis, R. H., Bowden, C. L., Thase, M. E., Miklowitz, D. J., Marangell, L. B. et al. (2009). Manic Symptoms during Depressive Episodes in 1380 Patients with Bipolar Disorder: Findings from the STEP-BD. American Journal of Psychiatry, 166, 173-181. http://dx.doi.org/10.1176/appi.ajp.2008.08050746

Judd, L. L., Akiskal, H. S., Schttler, P. J., Coryell, W., Endicott, J., Maser, J. D. et al. (2003). A Prospective Investigation of the Natural History of the Long-Term Weekly Symptomatic Status of Bipolar II Disorder. Archives of General Psychiatry, 60, 261-269. http://dx.doi.org/10.1001/archpsyc.60.3.261

Karfo, K., Sanou, A., Yaogo, A., Ouango, J. G., \& Ouedraogo, A. (2009) Aspects épidémiologiques et cliniques de la dépression chez la femme au CHU Yalgado Ouédraogo de Ouagadougou, Burkina Faso. Perspectives Psy, 48, 342-347. http://dx.doi.org/10.1051/ppsy/2009484342

Lempèrière, T., Feline, A., Ades, J., Hardy, P., \& Rouillon, F. (2006) Psychiatrie de l'adulte. Paris: Masson, 545 p.

M'boussou, M. (1981). Contribution à l'étude des états dépressifs au Sénégal (A propos de 417 observations à la clinique psychiatrique du CHU de Fann Dakar). Thèse de Médecine, Université Cheikh Anta Diop de Dakar, Dakar, 137 p.

Parker, G., \& Hadzi, P. (1996). Melancholia: A Disorder of Movement and Mood: A Phenomenological and Neurobiological Review. Cambridge: Cambridge University Press, 342 p. http://dx.doi.org/10.1017/CBO9780511759024

Thiam, M. H., Karfo, K., Sylla, A., Dassa, S. K., Sy, A., Ba, I., Faye, P. L., \& Gueye, M. (2008). Aspects cliniques et psychopathologiques de la dépression du post-partum: Rapport d'une série de onze cas sénégalais. Perspectives Psy, 47, 119-125. http://dx.doi.org/10.1051/ppsy/2008472119 


\section{Appendix}

Inquiry Form

I-File data

$\mathrm{N}^{\circ}$ of the file:

II-Personal Information

Surname: First name(s):

Age:

Sex:

Marital status:

Address:

Date of the consultation:

III-Prior medical history

Personal: somatic and psychiatric:

Lifetime events:

Family: somatic and psychiatric:

IV-Diagnosis made

$\mathrm{V}$-Symptoms exhibited

VI-Treatment

Hospitalization:

Outpatient: 